\title{
PREVALENCE OF INSULIN RESISTANCE AND ASSOCIATION WITH METABOLIC RISK FACTORS AND FOOD CONSUMPTION IN ADOLESCENTS - RECIFE/BRAZIL
} Prevalência de resistência à insulina e associação com fatores de risco metabólicos e consumo alimentar de adolescentes - Recife/Brasil

\author{
Maria Izabel Siqueira de Andradea,* (D), Juliana Souza Oliveira ${ }^{a}$ (D), \\ Vanessa Sá Leal ${ }^{a}$ (D), Niedja Maria da Silva Lima ${ }^{a}$ (D), Phelipe Bibiano Bezerra ${ }^{b}$ (D), \\ Emerson Rogério Costa Santiago ${ }^{a}$ (D), Pedro Israel Cabral de Lira ${ }^{a}$ (D)
}

\section{ABSTRACT}

Objective: To identify the prevalence of insulin resistance in adolescents and its associations with metabolic factors and food intake.

Methods: Cross-sectional study conducted with a stratified, complex, school-based sample. The subjects were adolescents $(n=1,081)$ who participated in the Study of Cardiovascular Risk in Adolescents in the city of Recife (Pernambuco, Brazil). We analyzed demographic, socioeconomic, behavioral, anthropometric, biochemical, and dietary variables. Insulin resistance was defined as HOMA-IR $>75^{\text {th }}$ percentile. A Poisson multivariate regression model with robust variance adjustment was used, and variables with $p \leq 0.05$ in the final model were considered statistically associated with insulin resistance.

Results: Median age was 14 years (interquartile range: $13-16$ years), and $25.3 \%$ of the sample showed insulin resistance. The variables associated with insulin resistance in the final model were age, body mass index-for-age (BMI/A), biochemical markers (triglycerides and high-density lipoprotein cholesterol) and saturated fat intake, with insulin resistance being more prevalent in individuals whose consumption of this type of fat was below the median of the sample distribution.

Conclusions: Insulin resistance was prevalent in the adolescents analyzed and was significantly associated with metabolic variables and saturated fat intake.

Keywords: Insulin resistance; Overweight; Food consumption; Adolescent.

\section{RESUMO}

Objetivo: Identificar a prevalência de resistência à insulina em adolescentes e verificar sua associação com variáveis metabólicas e com o consumo alimentar.

Métodos: Estudo transversal, de base escolar, com amostra do tipo estratificada e complexa. Os indivíduos analisados foram adolescentes ( $n=1.081$ ) participantes do Estudo de Riscos Cardiovasculares em Adolescentes (ERICA) na cidade de Recife (Pernambuco, Brasil). Foram coletadas variáveis demográficas, socioeconômicas, comportamentais, antropométricas, bioquímicas e do consumo alimentar. A resistência à insulina foi definida como HOMA-IR>percentil 75. Análises de regressão de Poisson com ajuste robusto da variância foram empregadas, sendo identificadas associações estatisticamente significativas quando $p \leq 0,05$.

Resultados:Aidademedianafoide 14anos(intervalointerquartilico=13-16) e a resistência à insulina foi evidenciada em 25,3\% da amostra. As variáveis quese associaramsignificativamente comaresistênciaà insulina no modelo final foram a faixa etária, o índice de massa corpórea por idade (IMC/I), marcadores bioquímicos (triglicerídeos e HDL-colesterol) e o consumo alimentar de gordura saturada, observando-se maior prevalência da resistência à insulina naqueles indivíduos que apresentaram a ingestão deste tipo de gordura abaixo da mediana da própria distribuição.

Conclusões: A resistência à insulina foi prevalente nos adolescentes avaliados e se associou significativamente com variáveis metabólicas e com o consumo alimentar de gordura do tipo saturada.

Palavras-chave: Resistência à insulina; Sobrepeso; Consumo alimentar; Adolescente.

*Corresponding author. E-mail: izabelandradee@hotmail.com (M.I.S. Andrade).

aniversidade Federal de Pernambuco, Recife, PE, Brazil.

'Centro Universitário Maurício de Nassau, Recife, PE, Brazil.

Received on January 21, 2019; approved on June 10, 2019; available online on February 26, 2020. 


\section{INTRODUCTION}

The epidemic trend and gradual increase in the prevalence of overweight and obesity in the Brazilian population are linked to a new profile of morbidity and mortality, in which there is a higher incidence of chronic non-communicable diseases even in the early stages of life. ${ }^{1,2}$ During adolescence, the bodily changes that are inherent to growth and sexual maturation may lead to excessive weight gain. This situation constitutes a primary risk factor for the development of insulin resistance (IR), which is a phenomenon that plays a major role in the emergence of cardiometabolic disorders. ${ }^{3}$

Dietary components can also influence insulin sensitivity. Evidence indicates a positive association between IR and the excessive intake of energy-dense foods rich in simple carbohydrates and fats, especially saturated and trans fats.,

Considering the methods proposed for detecting IR, the Homeostatic Model Assessment of Insulin Resistance (HOMA-IR) is the most used in epidemiological studies for being a fast, easy, low-cost method that effectively replaces the most sophisticated diagnostic techniques for IR. ${ }^{5}$

Thus, the present study aimed to identify the prevalence of IR in adolescents and its association with metabolic variables and food consumption.

\section{METHOD}

This is a school-based, cross-sectional study conducted with adolescents aged 12 to 17 years enrolled in the last three years of elementary school or high school at public and private institutions in a Brazilian city located in Northeastern Brazil. The subjects were part of the Study of Cardiovascular Risks in Adolescents (ERICA - Estudo de Riscos Cardiovasculares em Adolescentes), which was a national multicenter study that aimed to estimate the prevalence of factors associated with cardiovascular risk in adolescents. ${ }^{6}$

This study complied with the guidelines outlined in the Declaration of Helsinki and was approved by the Human Research Ethics Committee of the Federal University of Pernambuco (certificate number: 05185212.2.2002.5208). The adolescents and their legal guardians were informed about all procedures, risks, and benefits of the study and agreed to participate by signing the informed consent form.

A three-stage stratified sampling method was used to calculate the sample size: school, class, and students, selected with probability proportional to size. In the chosen schools, a survey was performed of classes and students in the target age range. Three classes were selected per school, and all students from the chosen classes were asked to participate in the study. Other studies have published details on the ERICA sampling process. ${ }^{6,7}$

As the national survey generated representative data for the country, different regions, and major cities, we decided to evaluate a sub-sample of the total population analyzed in the ERICA study. Thus, the present investigation included only adolescents enrolled in the morning period of 39 public and private schools in the city of Recife, obtaining a sample of 1,081 adolescents.

Demographic, socioeconomic, and behavioral data on the adolescents were collected with the aid of a Personal Digital Assistant (PDA). Properly trained researchers gathered information pertinent to nutritional status, biochemical markers, and food consumption. We investigated the following demographic and socioeconomic variables: gender, age, ethnicity, and maternal schooling. The individuals were also categorized according to socioeconomic status using the criteria of the Brazilian Market Research Association, ${ }^{8}$ and the results were dichotomized as high socioeconomic status (classes A1, A2, B1, and B2) or low socioeconomic status (classes $\mathrm{C}, \mathrm{D}$, and $\mathrm{E}$ ).

For the evaluation of nutritional status, weight was measured on an electronic scale with capacity for $200 \mathrm{~kg}$ and precision of $50 \mathrm{~g}$. Height was measured in duplicate using a portable stadiometer with precision of $0.1 \mathrm{~cm}$, assuming a maximum variation of $0.5 \mathrm{~cm}$ between the two measurements and calculating the mean. The reference standard to classify weight and height measures was that recommended by the World Health Organization (WHO), ${ }^{9}$ adopting the following cut-off points for categorizing the results: body mass index-for-age (BMI/A) $\mathrm{Z}$ score $<1$ - non-overweight individuals; BMI/A Z scores $\geq 1$ and $<2$ - overweight individuals, and $Z$ score $\geq 2$ - obese individuals. Waist circumference (WC) was calculated using a non-elastic measuring tape placed horizontally at the midpoint between the lower edge of the last rib and the iliac crest. WC values $\geq 90^{\text {th }}$ percentile of distribution were considered for the diagnosis of abdominal obesity. ${ }^{10}$ The waist-to-height ratio (WHtR) was calculated using the $\mathrm{WC}$ and height, with values equal to or greater than 0.5 established as the cut-off point for abdominal obesity. ${ }^{11}$

Plasma glucose was measured using the GOD-PAP method in the modular analyzer Roche equipment. The lipid profile included the determination of total cholesterol, high-density lipoprotein cholesterol (HDL-C), and triglycerides (TG), which were analyzed using the colorimetric enzymatic method in the modular analyzer Roche equipment. Low-density lipoprotein cholesterol (LDL-C) was calculated by the Friedewald formula. ${ }^{12}$ Plasma insulin was determined with immunoassays. Serum lipids were classified following the recommendations 
of the I Guideline for Preventing Atherosclerosis in Childhood and Adolescence. ${ }^{13}$ The HOMA-IR index was calculated from the values of glycemia and fasting insulinemia. Due to the different cut-off points found in the literature and their limitations, we adopted the $75^{\text {th }}$ percentile of the HOMA-IR distribution as the cut-off point for the diagnosis of IR because it represents the extreme of the HOMA-IR distribution, ${ }^{14,15}$ which is equivalent to 2.27 in the sample.

Food consumption was assessed using a single 24-hour dietary recall, which is a simple, fast, low-cost method that provides mean estimates of energy and nutrient intake. The questionnaire was administered in a face-to-face interview using the "Multiple-Pass Method." ${ }^{16}$ Dietary variables were collected with a specific software developed for the direct entry of information into netbooks. Consumption was estimated using the Nutritional Composition Table of Food Consumption in Brazil ${ }^{17}$ and the Table of Referred Measures for Food Consumption in Brazil. ${ }^{18}$ Quartiles $\left(25^{\text {th }}, 50^{\text {th }}\right.$, and $75^{\text {th }}$ percentiles) of energy and macronutrient intake were considered for statistical analysis.

Sexual maturation was self-reported and identified through indicative figures of the stages of sexual maturation proposed by Tanner, ${ }^{19}$ which are divided into three categories: Stage I — pre-puberty; Stages II, III, and IV — puberty; and Stage $\mathrm{V}$ - post-puberty.

The monthly frequency of tobacco and alcohol consumption and the physical activity level were investigated to collect behavioral data associated with metabolic risk. Smoking was defined as the use of one or more cigarettes in the 30 days prior to the interview, and binge drinking was established as the consumption of five or more shots of alcoholic beverages on a single occasion in the 30 days prior to the survey. ${ }^{20}$ Adopting the recommendations of the International Physical Activity Questionnaire (IPAQ), we classified the adolescents as "physically active" (those who reported practicing at least 60 minutes of moderate to vigorous physical activities five or more days per week) or "insufficiently active" (those who did not meet the criteria above). ${ }^{21}$

As sampling for the ERICA study involved stratification, clustering, and unequal probabilities, ${ }^{6}$ we performed the statistical analyses using the STATA software, version 14.0, adjusting the complex sampling design with the "survey" module. The explanatory variables were grouped into four hierarchically ordered levels: 1) socioeconomic factors; 2) behavioral factors; 3 ) individual factors (anthropometric and biochemical characteristics); 4) dietary factors, the latter of which was considered the most proximal level of the model. We determined the conceptual model assuming that factors predisposing to IR imply different hierarchical levels of outcome determination.
Initially, we conducted a bivariate analysis to determine associations between IR and the independent variables using simple Poisson regression. Variables with a $\mathrm{p}<0.20$ were incorporated into Poisson multivariate regression models with robust variance adjustment. Results were expressed as prevalence ratios and their respective 95\% confidence intervals. Variables with $\mathrm{p} \leq 0.05$ in the final model were considered statistically associated with IR.

\section{RESULTS}

The final sample was representative of 99,221 adolescents aged 12 to 17 years enrolled in the morning period of public and private schools of Recife. The sample comprised a higher percentage of public-school students $(60.1 \%)$ and those still in elementary school (53\%). The male gender accounted for $50.4 \%$ of the sample, and $50.9 \%$ were between 12 and 14 years of age (median: 14 years; interquartile range - IQR: 13 to 16 years). Students with lower socioeconomic status (72.1\%), whose ethnicity was classified as non-white (73.2\%), and whose mother had more than eight years of schooling (70.8\%) were predominant.

More than half of the adolescents evaluated were in the pubertal stage of sexual maturation (67.6\%), and the others were in the post-pubertal stage (32.4\%). Non-smokers (97.8\%) and those who did not consume alcoholic beverages (95.8\%) were predominant, and $54.9 \%$ of the individuals were considered physically active.

IR was confirmed in $25.3 \%$ of the population and was more common in females, adolescents aged between 12 and 14 years, those who did not consume alcoholic beverages, and individuals classified as physically inactive. Table 1 displays the distribution of IR according to demographic, socioeconomic (Level 1), and behavioral (Level 2) factors. Table 2 presents the association between the HOMA-IR index and both anthropometric and biochemical variables (Level 3). We found significant associations for all variables analyzed, except LDL-C. Concerning energy and macronutrient intake (Level 4), we identified inverse associations between IR and most food components in the unadjusted analysis (Tables 3 and 4).

After the statistical adjustments performed according to the pre-established hierarchical model, the variable that remained significantly associated with IR on Level 1 was age range; none of the variables on Level 2 were significantly associated with the outcome; on Level 3, the anthropometric index BMI/A and the biochemical markers TG and HDL-C remained statistically significant; and on Level 4, energy intake, total lipids, polyunsaturated fat, and monounsaturated fat had a statistically significant association with the outcome (Table 5). 


\section{DISCUSSION}

Studies addressing the association between IR (measured using the HOMA-IR index) and variables related to metabolic outcomes and food consumption among Brazilian adolescents are scarce in the literature. Research usually focuses on the occurrence of metabolic syndrome and its associated factors, which is an event frequently observed in these individuals, with rates ranging from 3.4 to $45.5 \%$, depending on the diagnostic criteria. ${ }^{1,22}$
Researchers recommend the use of the HOMA-IR index to assess IR in epidemiological investigations. ${ }^{5,23}$ However, there is no consensus in the literature regarding the cut-off point to use for adolescents, which leads to variations in the prevalence of IR reported. ${ }^{1,5,24}$ In the present study, we adopted the $75^{\text {th }}$ percentile of the HOMA-IR index, which corresponded to 2.27. This cut-off point is lower than the 3.16 recommended by I Guideline for

Table 1 Prevalence of insulin resistance in adolescents according to demographic, socioeconomic, and behavioral factors. Erica-Recife, 2013-2014.

\begin{tabular}{|c|c|c|c|c|c|}
\hline \multirow{2}{*}{ Variables } & \multicolumn{3}{|c|}{ Insulin Resistance } & \multirow{2}{*}{ PR $(95 \% \mathrm{Cl})$} & \multirow{2}{*}{ p-value } \\
\hline & $\mathbf{n}_{\text {observed }}$ & $\mathbf{n}_{\text {estimated }}$ & $\%$ & & \\
\hline \multicolumn{6}{|c|}{ Level 1 - Demographic/socioeconomic } \\
\hline \multicolumn{6}{|l|}{ Gender } \\
\hline Male & 89 & 11498 & 23.0 & Ref. & \multirow{2}{*}{$0.156^{*}$} \\
\hline Female & 182 & 13668 & 27.8 & $1.21(0.92,1.57)$ & \\
\hline \multicolumn{6}{|l|}{ Age range } \\
\hline $15-17$ years & 100 & 9730 & 20.0 & Ref. & \multirow{2}{*}{$0.001 \dagger$} \\
\hline $12-14$ years & 171 & 15435 & 30.6 & $1.53(1.21,1.93)$ & \\
\hline \multicolumn{6}{|l|}{ Ethnicity } \\
\hline White & 67 & 6353 & 23.8 & Ref. & \multirow{2}{*}{0.393} \\
\hline Others & 201 & 19151 & 26.4 & $1.10(0.87,1.40)$ & \\
\hline \multicolumn{6}{|c|}{ Sexual maturation } \\
\hline Post-puberty & 86 & 7668 & 23.8 & Ref. & \multirow{2}{*}{0.597} \\
\hline Puberty & 184 & 17445 & 26.0 & $1.09(0.78,1.52)$ & \\
\hline \multicolumn{6}{|c|}{ Maternal schooling } \\
\hline$>8$ years & 140 & 17045 & 24.3 & Ref. & \multirow{2}{*}{0.677} \\
\hline$\leq 8$ years & 65 & 7593 & 26.2 & $1.08(0.74,1.57)$ & \\
\hline \multicolumn{6}{|c|}{ Socioeconomic status } \\
\hline High & 49 & 6608 & 23.9 & Ref. & \multirow{2}{*}{0.956} \\
\hline Low & 136 & 17210 & 24.1 & $1.01(0.73,1.38)$ & \\
\hline \multicolumn{6}{|c|}{ Level 2 - Behavioral } \\
\hline \multicolumn{6}{|l|}{ Smoking } \\
\hline Yes & 3 & 487 & 22.5 & Ref. & \multirow{2}{*}{0.827} \\
\hline No & 268 & 24782 & 25.5 & $1.13(0.35,3.59)$ & \\
\hline \multicolumn{6}{|c|}{ Alcohol consumption } \\
\hline Yes & 9 & 529 & 12.6 & Ref. & \multirow{2}{*}{$0.121 *$} \\
\hline No & 240 & 23939 & 25.2 & $1.98(0.82,4.79)$ & \\
\hline \multicolumn{6}{|c|}{ Physical activity level } \\
\hline Active & 118 & 12345 & 22.7 & Ref. & \multirow{2}{*}{$0.178^{*}$} \\
\hline Inactive & 137 & 12542 & 28.0 & $1.23(0.90,1.68)$ & \\
\hline
\end{tabular}

PR: prevalence ratio; $95 \% \mathrm{Cl}$ : 95\% confidence interval; Ref: reference (1.00); ${ }^{*} \mathrm{p}<0.20 ; \uparrow p<0.05$ (simple Poisson regression). 
Preventing Atherosclerosis in Childhood and Adolescence, ${ }^{13}$ which is frequently used in Brazilian studies reporting similar or lower prevalence rates of IR in comparison to the present investigation (10 to $29 \%$ ). ${ }^{1,22,25}$

In a study conducted by $\mathrm{Li}$ et al. ${ }^{24}$ involving American adolescents aged between 12 and 19 years who participated in the 2005-2006 National Health and Nutrition Examination Survey (NHANES), the use of the $75^{\text {th }}$ percentile of the HOMA-IR index led to a lower prevalence rate of IR when compared to the one found in the present sample (8.7 vs.
25.3\%). We emphasize, however, that the NHANES sample was representative of the entire United States, and the population in the present study was representative only of the capital of the state of Pernambuco. Moreover, the authors cited did not report the cut-off point corresponding to $75^{\text {th }}$ percentile of the index.

Analyzing a representative sample of 2,716 Korean adolescents between the ages of 10 and 20 years, using the $95^{\text {th }}$ percentile of the HOMA-IR, Yi et al. ${ }^{5}$ found a lower prevalence rate of IR (9.8\%), which was higher among males $(10.9 \%)$

Table 2 Prevalence of insulin resistance in adolescents according to anthropometric and biochemical factors. Erica-Recife, 2013-2014.

\begin{tabular}{|l|c|c|c|c|c|}
\multirow{2}{*}{ Variables } & \multicolumn{2}{|c|}{ Insulin Resistance } & \multicolumn{2}{c|}{ PR $(95 \% \mathrm{Cl}) \quad$ P-value } \\
\cline { 2 - 4 } & $\mathrm{n}_{\text {observed }}$ & $\mathrm{n}_{\text {estimated }}$ & $\%$ & \\
\hline
\end{tabular}

Level 3 - Anthropometric/Biochemical

\begin{tabular}{|c|c|c|c|c|c|}
\hline \multicolumn{6}{|l|}{ BMI/A } \\
\hline Non-overweight & 122 & 10935 & 15.5 & Ref. & \multirow{3}{*}{$<0.001 \neq$} \\
\hline Overweight & 73 & 6536 & 35.4 & $2.28(1.65,3.15)$ & \\
\hline Obesity & 76 & 7695 & 73.7 & $4.74(3.53,6.36)$ & \\
\hline \multicolumn{6}{|l|}{ WC } \\
\hline Normal & 202 & 17776 & 20.1 & Ref. & \multirow{2}{*}{$<0.001 \neq$} \\
\hline High & 69 & 7433 & 68.5 & $3.40(2.61,4.43)$ & \\
\hline \multicolumn{6}{|l|}{ WHtR } \\
\hline Normal & 176 & 16074 & 19.0 & Ref. & \multirow{2}{*}{$<0.001 \neq$} \\
\hline Abdominal obesity & 95 & 9135 & 62.3 & $3.27(2.37,4.52)$ & \\
\hline \multicolumn{6}{|l|}{ Total cholesterol } \\
\hline Desirable & 122 & 11906 & 21.8 & Ref. & \multirow{3}{*}{$0.077 *$} \\
\hline Borderline & 73 & 6996 & 28.2 & $1.29(0.92,1.79)$ & \\
\hline High & 76 & 6264 & 31.6 & $1.45(1.03,2.01)$ & \\
\hline \multicolumn{6}{|l|}{ LDL-C } \\
\hline Desirable & 184 & 17525 & 24.1 & Ref. & \multirow{3}{*}{0.542} \\
\hline Borderline & 74 & 6497 & 29.7 & $1.23(0.84,1.80)$ & \\
\hline High & 13 & 1150 & 24.5 & $1.01(0.61,1.68)$ & \\
\hline \multicolumn{6}{|l|}{ HDL-C } \\
\hline Desirable & 105 & 8526 & 17.1 & Ref. & \multirow{2}{*}{$<0.001 \neq$} \\
\hline Low & 166 & 16639 & 33.7 & $1.97(1.54,2.50)$ & \\
\hline \multicolumn{6}{|l|}{ TG } \\
\hline Desirable & 171 & 15127 & 18.6 & Ref. & \multirow{3}{*}{$<0.001 \neq$} \\
\hline Borderline & 41 & 4201 & 44.7 & $2.39(1.79,3.20)$ & \\
\hline High & 59 & 5837 & 67.3 & $3.61(2.84,4.58)$ & \\
\hline
\end{tabular}

PR: prevalence ratio; Cl: 95\% confidence interval; BMI/A: body mass index-for-age; Ref: reference (1.00); WC: waist circumference; WHtR: waistto-height ratio; LDL-C: low-density lipoprotein cholesterol; HDL-C: high-density lipoprotein cholesterol; TG: triglycerides; ${ }^{*} p<0.20$; $† p<0.05$; $\neq p<0.001$ (simple Poisson regression). 
than females (8.6\%). In contrast, this disorder affected more female adolescents in the present study, which is in agreement with the findings of other studies, despite the different cutoff points used for the HOMA-IR index. ${ }^{1,22,23}$ The distinction in distribution between genders is due to differences in the changes in body composition between boys and girls and the action of hormones characteristic of the sexual maturation phase. ${ }^{22}$ However, we found no significant association between the stages of sexual maturation and the HOMA-IR in the present study. On the other hand, younger individuals (12 to 14 years) had a greater frequency of IR, and this association remained significant after the statistical adjustments. The occurrence of this event in younger individuals, probably in the early stages of puberty, may be explained by the fact that IR increases as a physiological response to puberty and the advance in age, returning to baseline levels after the growth spurt. ${ }^{1}$
In the unadjusted analysis, adolescents who did not drink alcohol were more affected by IR. However, this finding may have been due to the large number of non-drinkers in the sample. Although the consumption of moderate amounts of alcohol can lead to an improvement in insulin sensitivity in adults, ${ }^{26}$ this behavior should not be adopted as a measure for improving metabolic syndrome in adolescents.

A higher percentage of physically inactive individuals had a diagnosis of IR. This fact is worrisome, since a sedentary lifestyle contributes directly to weight gain, which is a primary risk factor for IR. ${ }^{5}$ In contrast, the regular practice of physical activity of moderate intensity can enhance the insulin response for up to 48 hours after physical training, ${ }^{27}$ help maintain an ideal body weight, and improve both physical and psychological quality in adolescence and adulthood.

Table 3 Prevalence of insulin resistance in adolescents according to energy and carbohydrate intake. Erica-Recife, 2013-2014.

\begin{tabular}{|c|c|c|c|c|c|}
\hline \multirow{2}{*}{ Variables } & \multicolumn{3}{|c|}{ Insulin Resistance } & \multirow{2}{*}{ PR $(95 \% \mathrm{Cl})$} & \multirow{2}{*}{ p-value } \\
\hline & $\mathrm{n}_{\text {observed }}$ & $\mathbf{n}_{\text {estimated }}$ & $\%$ & & \\
\hline \multicolumn{6}{|c|}{ Level 4 - Food consumption } \\
\hline \multicolumn{6}{|l|}{ Energy intake (kcal) } \\
\hline$<1761.44$ & 89 & 8953 & 38.3 & $2.17(1.56,3.01)$ & \multirow{4}{*}{$<0.001 \dagger$} \\
\hline $1761.44-2422.74$ & 71 & 5755 & 24.7 & $1.40(0.93,2.11)$ & \\
\hline 2422.74-3237.17 & 63 & 5713 & 22.3 & $1.26(0.91,1.73)$ & \\
\hline$>3237.17$ & 48 & 4744 & 17.6 & Ref. & \\
\hline \multicolumn{6}{|l|}{ Carbohydrates (g) } \\
\hline$<230.8$ & 90 & 8417 & 34.9 & $1.88(1.33,2.67)$ & \multirow{4}{*}{$<0.001 \dagger$} \\
\hline $230.8-320.8$ & 72 & 6303 & 27.1 & $1.46(0.93,2.28)$ & \\
\hline $320.8-434.5$ & 51 & 4798 & 18.5 & Ref. & \\
\hline$>434.5$ & 58 & 5647 & 21.7 & $1.17(0.76,1.79)$ & \\
\hline \multicolumn{6}{|l|}{ Refined sugar (g) } \\
\hline$<86.1$ & 76 & 7495 & 29.3 & $1.46(0.97,2.21)$ & \multirow{4}{*}{$0.097^{*}$} \\
\hline $86.1-137.3$ & 83 & 7272 & 28.5 & $1.42(0.99,2.03)$ & \\
\hline $137.3-195.4$ & 59 & 5383 & 23.4 & $1.17(0.67,2.03)$ & \\
\hline$>195.4$ & 53 & 5015 & 20.0 & Ref. & \\
\hline \multicolumn{6}{|l|}{ Added sugar (g) } \\
\hline$<60.8$ & 80 & 8308 & 32.9 & $1.61(1.07,2.40)$ & \multirow{4}{*}{$0.126^{*}$} \\
\hline $60.8-104.4$ & 68 & 6188 & 24.7 & $1.21(0.85,1.72)$ & \\
\hline 104.4-163.0 & 71 & 5646 & 23.2 & $1.13(0.70,1.82)$ & \\
\hline$>163.0$ & 52 & 5024 & 20.4 & Ref. & \\
\hline
\end{tabular}

PR: prevalence ratio; Cl: 95\% confidence interval; Ref.: reference (1.00); ${ }^{*}<<0.20 ; \uparrow p<0.05 ; \neq p<0.001$ (simple Poisson regression). 
Table 4 Prevalence of insulin resistance in adolescents according to dietary fat intake. Erica-Recife, 2013-2014.

\begin{tabular}{|l|c|c|c|c|c|}
\multirow{2}{*}{ Variables } & \multicolumn{3}{|c|}{ Insulin Resistance } & \multirow{2}{*}{ PR $(95 \% \mathrm{Cl})$} & p-value \\
\cline { 2 - 4 } & $\mathrm{n}_{\text {observed }}$ & $\mathrm{n}_{\text {estimated }}$ & $\%$ & &
\end{tabular}

Level 4 - Food consumption

Total lipids (g)

\begin{tabular}{|c|c|c|c|c|c|}
\hline$<54.5$ & 83 & 8369 & 35.6 & $1.76(1.20,2.57)$ & \multirow{4}{*}{$0.028 \dagger$} \\
\hline $54.5-80.3$ & 79 & 6320 & 26.4 & $1.30(0.89,1.92)$ & \\
\hline $80.3-115.9$ & 55 & 5371 & 20.3 & $1.01(0.65,1.55)$ & \\
\hline$>115.9$ & 54 & 5105 & 20.2 & Ref. & \\
\hline \multicolumn{6}{|c|}{ Saturated fat (g) } \\
\hline$<18.8$ & 82 & 8015 & 34.5 & $1.83(1.21,2.78)$ & \multirow{4}{*}{$0.032 t$} \\
\hline $18.8-27.9$ & 71 & 6384 & 25.9 & $1.37(0.86,2.21)$ & \\
\hline $27.9-42.9$ & 67 & 5892 & 23.2 & $1.23(0.80,1.89)$ & \\
\hline$>42.9$ & 51 & 4874 & 18.7 & Ref. & \\
\hline
\end{tabular}

Polyunsaturated fat $(\mathrm{g})$

\begin{tabular}{|c|c|c|c|c|c|}
\hline$<8.7$ & 82 & 7726 & 33.8 & $1.53(1.01,2.30)$ & \multirow{4}{*}{$0.199 *$} \\
\hline $8.7-13.5$ & 70 & 5523 & 23.3 & $1.05(0.69,1.60)$ & \\
\hline $13.5-22.0$ & 63 & 6229 & 23.1 & $1.04(0.72,1.50)$ & \\
\hline$>22.0$ & 56 & 5687 & 22.1 & Ref. & \\
\hline
\end{tabular}

\begin{tabular}{l|l|l|l|c|}
\hline Omega-6 $(\mathrm{g})$ & \multicolumn{1}{l}{} \\
\hline$<7.6$ & 81 & 7601 & 33.3 & $1.51(0.98,2.32)$ \\
\hline $7.6-11.8$ & 70 & 5651 & 23.7 & $1.07(0.75,1.51)$ \\
\hline $11.8-19.2$ & 63 & 5916 & 22.1 & Ref. \\
\hline$>19.2$ & 57 & 5997 & 23.3 & $1.05(0.71,1.55)$ \\
\hline
\end{tabular}

Omega-3 (g)

\begin{tabular}{|l|l|l|l|c|}
\hline$<0,9$ & 78 & 7331 & 32.8 & $1.52(1.01,2.29)$ \\
\hline $0.9-1.4$ & 64 & 5284 & 21.5 & Ref. \\
\hline $1.4-2.3$ & 73 & 6771 & 24.7 & $1.14(0.73,1.79)$ \\
\hline$>2.3$ & 56 & 5779 & 23.1 & $1.07(0.70,1.62)$ \\
\hline
\end{tabular}

Monounsaturated fat $(\mathrm{g})$

\begin{tabular}{|l|c|c|c|c|}
\hline$<17.5$ & 87 & 8346 & 35.7 & $1.86(1.27,2.71)$ \\
\hline $17.5-26.4$ & 72 & 5989 & 24.9 & $1.29(0.91,1.85)$ \\
\hline $26.4-38.9$ & 62 & 5878 & 22.6 & $1.17(0.77,1.77)$ \\
\hline$>38.9$ & 50 & 4951 & 19.2 & Ref. \\
\hline
\end{tabular}

Dietary cholesterol (g)

\begin{tabular}{|l|c|c|c|c|}
\hline$<140.1$ & 69 & 6920 & 30.0 & $1.35(0.81,2.26)$ \\
\hline $140.1-228.3$ & 76 & 6799 & 27.3 & $1.23(0.88,1.71)$ \\
\hline $228.3-396.4$ & 58 & 5723 & 22.5 & $1.01(0.71,1.43)$ \\
\hline$>396.4$ & 68 & 5724 & 22.1 & Ref. \\
\hline
\end{tabular}

Trans fat $(g)$

\begin{tabular}{|l|l|l|l|c|}
\hline$<1.0$ & 74 & 7290 & 28.6 & $1.33(0.96,1.84)$ \\
\hline $1.0-1.7$ & 69 & 6137 & 25.3 & $1.18(0.92,1.52)$ \\
\hline $1.7-3.1$ & 68 & 6393 & 26.0 & $1.21(0.82,1.79)$ \\
\hline$>3.1$ & 60 & 5345 & 21.4 & Ref. \\
\hline
\end{tabular}

PR: prevalence ratio; Cl: $95 \%$ confidence interval; Ref.: reference (1.00); * $p<0.20 ; \uparrow p<0.05 ; \ddagger p<0.001$ (simple Poisson regression). 
Table 5 Adjusted prevalence ratios of insulin resistance in adolescents according to explanatory variables. Erica-Recife, 2013-2014.

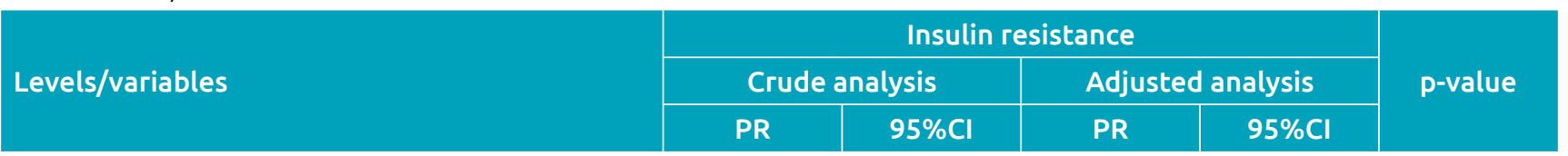

Level 1 - Demographic/socioeconomic

Age range

\begin{tabular}{l|l|l|l|l|l}
\hline $15-17$ years & Ref. & & Ref. & & \\
\hline $12-14$ years & 1.53 & $(1.21,1.93)$ & 1.54 & $(1.23,1.95)$ & $0.001 *$ \\
\hline
\end{tabular}

Level 3 - Anthropometric/biochemical

\begin{tabular}{|c|c|c|c|c|c|}
\hline \multicolumn{6}{|l|}{$\mathrm{BMI} / \mathrm{A}$} \\
\hline Non-overweight & Ref. & & Ref. & & \\
\hline Overweight & 2.28 & $(1.65,3.15)$ & 1.92 & $(1.34,2.75)$ & $0.001 *$ \\
\hline Obesity & 4.74 & $(3.53,6.36)$ & 3.14 & $(2.22,4.46)$ & $<0.001 \dagger$ \\
\hline \multicolumn{6}{|l|}{ TG } \\
\hline Desirable & Ref. & & Ref. & & \\
\hline Borderline & 2.39 & $(1.79,3.20)$ & 1.67 & $(1.23,2.26)$ & $0.002 *$ \\
\hline High & 3.61 & $(2.84,4.58)$ & 2.13 & $(1.71,2.67)$ & $<0.001 \dagger$ \\
\hline \multicolumn{6}{|l|}{ HDL-C } \\
\hline Desirable & Ref. & & Ref. & & \\
\hline Low & 1.97 & $(1.54,2.50)$ & 1.51 & $(1.0,2.28)$ & $0.050 *$ \\
\hline \multicolumn{6}{|c|}{ Level 3 - Food consumption } \\
\hline \multicolumn{6}{|l|}{ Energy intake (kcal) } \\
\hline$<1761.44$ & 2.17 & $(1.56,3.01)$ & 4.23 & $(1.32,13.5)$ & $0.016 *$ \\
\hline $1761.44-2422.74$ & 1.40 & $(0.93,2.11)$ & 2.79 & $(0.93,8.29)$ & 0.064 \\
\hline $2422.74-3237.17$ & 1.26 & $(0.91,1.73)$ & 2.35 & $(1.11,4.99)$ & $0.027 *$ \\
\hline$>3237.17$ & Ref. & & Ref. & & \\
\hline \multicolumn{6}{|l|}{ Total lipids (g) } \\
\hline$<54.5$ & 1.76 & $(1.20,2.57)$ & 0.53 & $(0.17,1.61)$ & 0.256 \\
\hline $54.5-80.3$ & 1.30 & $(0.89,1.92)$ & 0.71 & $(0.28,1.78)$ & 0.463 \\
\hline $80.3-115.9$ & 1.01 & $(0.65,1.55)$ & 0.40 & $(0.17,0.91)$ & $0.032 *$ \\
\hline$>115.9$ & Ref. & & Ref. & & \\
\hline \multicolumn{6}{|c|}{ Polyunsaturated fat (g) } \\
\hline$<8.7$ & 1.53 & $(1.01,2.30)$ & 0.66 & $(0.38,1.15)$ & 0.144 \\
\hline $8.7-13.5$ & 1.05 & $(0.69,1.60)$ & 0.57 & $(0.37,0.87)$ & $0.012 *$ \\
\hline $13.5-22.0$ & 1.04 & $(0.72,1.50)$ & 0.92 & $(0.60,1.42)$ & 0.718 \\
\hline$>22.0$ & Ref. & & Ref. & & \\
\hline \multicolumn{6}{|c|}{ Monounsaturated fat (g) } \\
\hline$<17.5$ & 1.86 & $(1.27,2.71)$ & 1.40 & $(0.52,3.78)$ & 0.488 \\
\hline $17.5-26.4$ & 1.29 & $(0.91,1.85)$ & 1.05 & $(0.40,2.73)$ & 0.914 \\
\hline 26.4-38.9 & 1.17 & $(0.77,1.77)$ & 1.78 & $(1.02,3.08)$ & $0.040 *$ \\
\hline$>38.9$ & Ref. & & Ref. & & \\
\hline
\end{tabular}

PR: prevalence ratio; Cl: 95\% confidence interval; Ref.: reference (1.00); BMI/A: body mass index-for-age; TG: triglycerides; HDL-C: highdensity lipoprotein cholesterol; ${ }^{*} \mathrm{p} \leq 0.05 ; \uparrow p<0.001$ (Poisson regression with robust variance adjustment). Level 1 adjusted for stage of sexual maturation. Level 3 adjusted for variables of level 1 and stage of sexual maturation. Level 4 adjusted for variables of levels 1 and 3 and stage of sexual maturation. 
Overweight and obese adolescents had a threefold higher prevalence rate of IR compared to non-overweight adolescents. According to Lavrador et al., ${ }^{28} \mathrm{IR}$ is strongly associated with the severity of obesity, and a dose-response gradient can be inferred from this association.

The type of body fat distribution can also determine the development of IR, with greater risk observed mainly among individuals with fat accumulated in the visceral or abdominal region, which concentrates a larger amount of cells that activate the inflammatory state, thereby contributing to IR. ${ }^{26}$ In a cross-sectional study using the $75^{\text {th }}$ percentile as the cut-off point for 486 children and adolescents aged 5 to 15 years, Burrows et al. ${ }^{29}$ found a direct association between the HOMA-IR index and WC; the authors also identified inadequate levels of TG and HDL-C, which is in agreement with the present findings. When assessing Brazilian adolescents between 10 and 19 years of age with HOMA-IR subdivided in percentiles, Rocco et al. ${ }^{30}$ found that a higher percentile of the index denoted a greater risk for the other metabolic variables analyzed. Likewise, Gobato et al. ${ }^{1}$ analyzed the distribution of the HOMA-IR in tertiles and verified that the mean of all body composition indicators assessed in the study, including BMI and WC, increased with the rise in HOMA-IR scores.

The associations found between the HOMA-IR index and both TG and HDL-C in the adjusted analysis may have occurred because overweight and obesity increase the number of adipocytes, consequently releasing free fatty acids into the bloodstream. ${ }^{26}$ Moreover, IR raises the serum levels of LDL-C, resulting in reduced HDL-C concentrations, the activation of which depends on the degradation of LDL-C. ${ }^{1}$

Our study demonstrated an inverse association between energy intake and IR. Regarding the consumption of total and polyunsaturated fats, we identified a protective effect. In contrast, the consumption of monounsaturated fats did not show benefits in terms of lower prevalence of the outcome, similar to the study by Kahleova et al., in 2019. ${ }^{4}$

Epidemiological data regarding the influence of diet on IR in adolescents are scarcely available in the literature, and this issue requires further clarification. In a cross-sectional study comprising 100 female adolescents aged between 12 and 14 years, enrolled in public schools in the city of Viçosa (Southeastern Brazil), Faria et al. ${ }^{25}$ found a higher intake of saturated fat among adolescents without metabolic syndrome, which was the outcome analyzed. According to the authors, this finding may have been due to information bias, as overweight adolescents often underestimate their current consumption of fats, or reverse causality (e.g., overweight and obese adolescents may have been on a diet to lose weight). Indeed, these factors must also be taken into account when interpreting the dietary data reported in the present investigation. Nonetheless, the harmful effects of the excessive consumption of foods rich in refined sugar as well as saturated and trans fats are well established in the literature. ${ }^{3,4,25}$ Inadequate eating habits combined with physical inactivity favor overweight and the establishment of a pro-inflammatory condition that contributes to the development of IR. ${ }^{3,4}$

The present study involved a representative sample of adolescents and described data from a place with no previous research on the subject. However, some limitations should be considered. The cross-sectional design does not allow us to determine cause-and-effect relationships. The administration of just one 24-hour dietary recall only reveals the current consumption, which also renders the determination of causality impossible. Moreover, the use of self-reported data may increase the risk of information bias. Another factor to consider was the different cut-off points used for the HOMA-IR in the articles consulted, which hinders the comparison of results.

In short, the present findings reveal that IR was prevalent in the population analyzed. This is an issue of concern, as the sample consisted of individuals in the early stages of life. The associations between the HOMA-IR index and variables related to metabolic outcomes enabled the recognition of the factors most connected to IR, which can assist in the implementation of public health strategies for preventing this disorder in adolescents by strengthening actions directed at addressing predisposing conditions, especially overweight. Further studies on food consumption in this age group are necessary and should take into account eating behaviors and habits in a more global way to allow better recognition of food characteristics that pose a risk for the development of IR and metabolic disorders in adolescence.

\section{Funding}

This work was funded by the Financiadora de Estudos e Projetos (FINEP), Brazil (grant number 01090421) and the Conselho Nacional de Desenvolvimento Científico e Tecnológico, Brazil (grant numbers 565037/2010-2 and 405.009/2012-7).

\section{Conflict of interests}

The authors declare no conflict of interests. 


\section{REFERENCES}

1. Gobato $A O$, Vasques $A C$, Zambon MP, Barros Filho AZ, Hessel G. Metabolic syndrome and insulin resistance in obese adolescents. Rev Paul Pediatr. 2014;32:52-65. http:// dx.doi.org/10.1590/S0103-05822014000100010

2. Conde WL, Monteiro CA. Nutrition transition and double burden of undernutrition and excess of weight in Brazil. Am J Clin Nutr. 2014;100:1617S-22S. https://doi.org/10.3945/ ajcn.114.084764

3. White J, Jago R, Thompson JL. Dietary risk factors for the development of insulin resistance in adolescent girls: a 3-year prospective study. Public Health Nutr. 2014;17:361-8. https://doi.org/10.1017/S1368980012004983

4. Kahleova H, Hlozkova A, Fleeman R, Fletcher K, Holubkov R, Barnard ND. Fat quantity and quality, as part of a low-fat, vegan diet, are associated with changes in body composition, insulin resistance, and insulin secretion. A 16-week randomized controlled trial. Nutrients. 2019;11:E615. https://doi.org/10.3390/nu11030615

5. Yi KH, Hwang JS, Kim EY, Lee SH, Kim DH, Lim JS. Prevalence of insulin resistance and cardiometabolic risk in Korean children and adolescents: a population-based study. Diabetes Res Clin Prac. 2014;103:106-13. https://doi.org/10.1016/j. diabres.2013.10.021

6. Vasconcellos MT, Silva PL, Szklo M, Kuschnir MC, Klein KH, Abreu $G A$, et al. Sampling design for the Study of Cardiovascular Risk in Adolescents (ERICA). Cad Saude Publica. 2015;31:921-30. http://dx.doi.org/10.1590/0102-311X00043214

7. Bloch KV, Szklo M, Kuschnir MC, Abreu GA, Barufaldi LA, Klein $\mathrm{CH}$, et al. The Study of Cardiovascular Risk in AdolescentsERICA: rationale, design and sample characteristics of a national survey examining cardiovascular risk factor profile in Brazilian adolescents. BMC Public Health. 2015;15:94. https://doi.org/10.1186/s12889-015-1442-x

8. Associação Brasileira de Empresas de Pesquisa. Dados com base no Levantamento Sócio Econômico 2010. São Paulo: ABEP; 2010

9. World Health Organization. WHO Child Growth Standards: length/height-for-age, weight-for-age, weight-for-length, weight-for-height and body mass index-for-age: methods and development. Geneva: WHO; 2007

10. International Diabetes Federation. IDF consensus definition of the metabolic syndrome in children and adolescents. Brussels: IDF; 2007.

11. Ashwell M, Hsieh SD. Six reasons why the waist-to-height ratio is a rapid and effective global indicator for health risks of obesity and how its use could simplify the international public health message on obesity. Int J Food Sci Nutr. 2005;56:303-7. https://doi.org/10.1080/09637480500195066

12. Friedewald WT, Levy RI, Fredrickson DS. Estimation of the concentration of low-density lipoprotein cholesterol in plasma, without use of the preparative ultracentrifuge. Clin Chem. 1972;18:499-502.

13. Sociedade Brasileira de Cardiologia. I Diretriz de prevenção da aterosclerose na infância e na adolescência. Arq Bras Cardiol. 2005;5 (Suppl. 6):3-36. http://dx.doi.org/10.1590/ s0066-782X2005002500001
14. Andrade MI, Oliveira JS, Leal VS, Lima NM, Costa EC Aquino NB, et al. Identification of cutoff points for Homeostatic Model Assessment for Insulin Resistance index in adolescents: systematic review. Rev Paul Pediatr. 2016;34:234-42. http://dx.doi.org/10.1016/j. rppede.2016.01.004

15. Baba R, Koketsu M, Nagashima M, Tamakoshi A, Inasaka H. Role of insulin resistance in non-obese adolescents. Nagoya J Med Sci. 2010;72:161-6.

16. Conway JM, Ingwersen LA, Vinyard BT, Moshfegh AJ. Effectiveness of the US Department of Agriculture 5-step multiple-pass method in assessing food intake in obese and nonobese women. Am J Clin Nutr. 2003;77:1171-8. https:// doi.org/10.1093/ajcn/77.5.1171

17. Brazil - Ministério do Planejamento, Orçamento e Gestão. Instituto Brasileiro de Geografia e Estatística. Pesquisa de Orçamentos Familiares (POF) 2008-2009: Tabela de composição nutricional dos alimentos consumidos no Brasil. Rio de Janeiro: IBGE; 2011.

18. Brazil - Ministério do Planejamento, Orçamento e Gestão. Instituto Brasileiro de Geografia e Estatística. Pesquisa de orçamentos familiares 2008-2009: Tabela de medidas referidas para os alimentos consumidos no Brasil. Rio de Janeiro: IBGE; 2011.

19. Tanner JM. Growth at adolescence. In: Malina RM, Bouchard C, editor. Growth, maturation, and physical activity. Champaign: Human Kinetics Books; 1991.

20. Kann L, Kinchen S, Shanklin SL, Flint KH, Kawkins J, Harris WA, et al. Youth risk behavior surveillance - United States, 2013. MMWR Suppl. 2014;63:1-168.

21. Guedes DP, Lopes CC, Guedes JE. Reproducibility and validity of International Physical Activity Questionnaire in adolescents. Rev Bras Med Esp. 2005;11:151-8. http:// dx.doi.org/10.1590/S1517-86922005000200011

22. Faria ER, Faria FR, Franceschini SC, Peluzio MC, Sant'Ana LF, Novaes JF, et al. Insulin resistance and components of metabolic syndrome, analysis by gender and stage of adolescence. Arq Bras Endocrinol Metab. 2014;58:610-8. http://dx.doi.org/10.1590/0004-2730000002613

23. Silva CC, Zambon MP, Vasques AC, Camilo DF, Rodrigues AM, Góes MA, et al. Homeostatic model assessment of adiponectin (HOMA-Adiponectin) as a surrogate measure of insulin resistance in adolescents: comparison with the hyperglycaemic clamp and homeostatic model assessment of insulin resistance. PLoS One. 2019;14:e0214081. https:// doi.org/10.1371/journal.pone.0214081

24. Li C, Ford ES, Zhao G, Mokdad AH. Prevalence of pre-diabetes and its association with clustering of cardiometabolic risk factors and hyperinsulinemia among U.S. adolescents: National Health and Nutrition Examination Survey 2005-2006. Diabetes Care. 2009;32:342-7. https://doi. org/10.2337/dc08-1128

25. Faria ER, Faria FR, Pinto CA, Franceschini SC, Peluzio MC, Priore SE. Consumo alimentar e síndrome metabólica em adolescentes do sexo feminino. RASBRAN. 2014;6:21-8. 
26. Yokoyama H. Beneficial effects of ethanol consumption on insulin resistance are only applicable to subjects without obesity or insulin resistance; drinking is not necessarily a remedy for metabolic syndrome. Int J Environ Res Public Health. 2011;8:3019-31. https://doi.org/10.3390/ijerph8073019

27. Keshel TE, Coker RH. Exercise training and insulin resistance: a current review. J Obes Weight Loss Ther. 2015;5:S5-003. https://doi.org/10.4172/2165-7904.S5-003

28. Lavrador MS, Abbes PT, Escrivão MA, Taddei JA. Cardiovascular risks in adolescents with different degrees of obesity. Arq Bras Cardiol. 2011;96:205-11. https://doi.org/10.1590/ s0066-782x2010005000166
29. Burrows RA, Leiva LB, Weisstaub G, Lera LM, Albala CB, Blanco E. High HOMA-IR, adjusted for puberty, relates to the metabolic syndrome in overweight and obese Chilean youths. Pediatr Diabetes. 2011;12:212-8. https://doi. org/10.1111/j.1399-5448.2010.00685.x

30. Rocco ER, Mory DB, Bergamim CS, Valente F, Miranda VL, Frederico B, et al. Optimal cutoff points for body mass index, waist circumference and HOMA-IR to identify a cluster of cardiometabolic abnormalities in normal glucose-tolerant Brazilian children and adolescents. Arq Bras Endocrinol Metabol. 2011;55:638-45. http://dx.doi.org/10.1590/S000427302011000800020 